\title{
Improvement of the Carbon Electrode Treatment to Obtain Bioanodes for Microbial Electrolysis Cell (MEC)
}

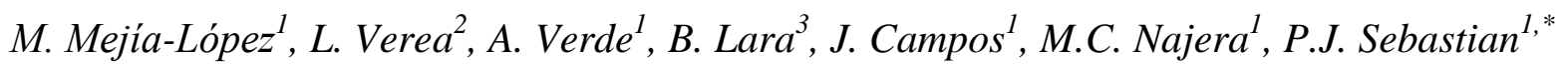 \\ ${ }^{1}$ Instituto de Energías Renovables, Universidad Nacional Autónoma de México, Temixco, 62580, \\ Morelos, México \\ ${ }^{2}$ Centro de Investigación y Desarrollo Tecnológico en Energías Renovables, Universidad de Ciencias \\ y artes de Chiapas, Tuxtla Gutiérrez 29039, Chiapas, México \\ ${ }_{3}^{3}$ Facultad de Ingeniería, Universidad Autónoma de San Luis Potosí, Av. Dr. Manuel Nava 8, Zona \\ Universitaria Poniente, San Luis Potosí, S.L.P. 78290, México. \\ *E-mail: sjp@ier.unam.mx
}

doi: $10.20964 / 2018.04 .64$

Received: 6 March 2017 / Accepted: 8 August 2017 / Published: 6 March 2018

\begin{abstract}
In this work a process to modify the surface of carbon electrode was studied with the goal of improving the adherence of the bacteria on it. This study was performed through an experimental design to determine the effect of the parameters tested for the biofilm formation. The biofilms were analyzed with cyclic voltammetry technique and the kinetic parameters of alpha and $k_{\text {app }}$ were analyzed with a statistical tool called the surface response. The parameters varied in the treatment were: concentration of the substrate, temperature, potential applied and time of the treatment. The results showed differences on the biofilm formed mainly with the concentration of the substrate and the potential applied in the electrode treatment. An alpha of 0.5 obtained suggests an electron transport due to the confined redox compounds within the biofilm and the $k_{a p p}$ varied from $0.07 \mathrm{~s}^{-1}$ to $0.4 \mathrm{~s}^{-1}$. Finally, the biofilms formed were used in a MEC to probe their capability as bio-anodes for hydrogen production and was obtained a production of $0.21 \mathrm{~m}^{3} \mathrm{H}_{2} / \mathrm{m}^{3} \mathrm{~d}$.
\end{abstract}

Keywords: Biofilm, bioanode, hydrogen, MEC

\section{$\underline{\text { FULL TEXT }}$}

C) 2018 The Authors. Published by ESG (www.electrochemsci.org). This article is an open access article distributed under the terms and conditions of the Creative Commons Attribution license (http://creativecommons.org/licenses/by/4.0/). 